\title{
ENTRE OPORTUNIDADES Y OBSTÁCULOS. \\ LO QUE DEVELA EL PROCESO DE INSERCIÓN \\ Del queso Cotija artesanal \\ EN LA ECONOMÍA FORMAL
}

\section{Between Opportunities and Obstacles. The Process of Insertion of Artis anal Cotija Cheese into The Formal Economy}

\section{Esteban Barragán López ${ }^{1}$}

Resumen: Entre la diversidad de productos procesados artesanalmente en México, orillados a moverse en la informalidad económica, y el modelo de desarrollo basado en la estandarización de procesos y productos, así como en la formalización empresarial sin distingo, se viene ensanchando un abismo cada día más difícil de franquear.

De un lado se debaten por permanecer vivas las culturas que siguen guiando su rumbo por las tradiciones seculares, cuyas objetivaciones derivan en una amplia gama de patrimonios bioculturales, sus referentes históricos, territoriales e identitarios. Del otro lado se pretende imponer a tabla rasa un modelo de desarrollo unilineal, uniformador de lógicas y prácticas económicas, favorable a fuertes intereses de los capitales transnacionales ante los cuales se alinean los gobernantes. La experiencia emanada del proceso de patrimonialización del queso Cotija devela que las oportunidades de sobrevivencia de los innumerables productos procesados artesanalmente y de las diversas formas de vida que los sustentan, son socavadas por los obstáculos que les impone un modelo económico unilineal.

\footnotetext{
${ }^{1}$ Profesor-Investigador, El Colegio de Michoacán, México.

Correo electrónico: estebar@hotmail.com

Fecha de recepción: 1406 16; Fecha de aceptación: 161116.

(cc) EY-NC-ND Páginas 84-111.
} 
Palabras clave: patrimonio biocultural, patrimonialización, densidad cultural, Marca Colectiva, producción de alimentos.

Abstract: Between the diversity of artisanally-elaborated products in Mexico shunted to circulate in a sea of economic informality, and the development model based on standardizing processes and products through entrepreneurial formalization that no longer distinguishes among economic activities, we observe the widening of an abyss that is increasingly difficult to bridge. On one side of the debate are those who recognize the importance of keeping alive cultures that follow paths laid down by secular traditions whose objectifications generate a broad range of biocultural patrimonies that constitute their historical, territorial and identitary referents; on the other, those who seek to impose a 'blank slate'; i.e., a unilinear development model that standardizes all economic logics and practices to favor the vested interests of transnational capital with which the governments of most countries are now aligned. The experience that emerges from the process of the patrimonialization of Cotija Cheese illustrates the possibilities and obstacles involved in bridging this abyss.

Keywords: biocultural patrimony, patrimonialization, cultural density, collective brand, food production.

\section{Introducción}

En este trabajo pretendo exponer las principales expectativas e impedimentos que hemos detectado tanto de la parte de los productores artesanos como de las instituciones y del mercado en los procesos de patrimonialización de bienes culturales, específicamente al tratar de insertar los productos alimenticios procesados artesanalmente en la economía formal. Se toma como eje rector del análisis el proceso de patrimonialización del queso Cotija, puesto en marcha desde hace 18 años (Barragán y Ovando, 2015). En este caso, como en otros procesos de activación y apropiación de bienes patrimoniales, se ve la oportunidad de salvaguardar y dar viabilidad a la producción en pequeña escala y a 
las actividades artesanales — que en muchos casos se encuentran asociadas - como medio y forma de vida de los productores artesanos.

Sin embargo, el caso del queso Cotija nos enseña que en dichos procesos se enfrenta un sinnúmero de dificultades al tiempo que también abren debates que desnudan una problemática urgente de abordar en amplios foros sociales (Linck y Barragán, 2015). Los marcos legales e institucionales, con sus normativas y burocracias, así como los requerimientos de los mercados y exigencias de las grandes empresas, no sólo son inadecuados frente a la situación y condiciones económicas y/o culturales de los artesanos y de los productores primarios a pequeña escala, quienes frecuentemente son a la vez transformadores artesanales e incluso semi industriales, sino que dichos marcos normativos y exigencias están perjudicando cada vez con mayor contundencia y peligro contra la continuidad cultural y la viabilidad económica que durante siglos han demostrado tener los productores artesanos del país. De esta manera, se atenta contra la diversidad de sistemas de producción tradicionales y procesos artesanales, particularmente en los sistemas agroalimentarios locales (Boucher y Reyes, 2011), a los que las instituciones gubernamentales no ven con nitidez o, aún más, los tratan de desaparecer. ${ }^{2}$

De ahí que generalmente lejos de favorecer el logro de los objetivos de activación patrimonial, que son la revaloración, apropiación local, potenciación y, en fin, la revitalización y continuidad del patrimonio biocultural, ${ }^{3}$ se ponen en riesgo de vaciar de contenido, adulterar y mercantilizar dichos patrimonios y, con ello, las abundantes tradiciones que aún se mantienen vivas en los diversos pueblos y regiones del país. $\mathrm{Al}$ no poder los artesanos cumplir con las condiciones que exigen las instituciones en su descontextualizado afán de convertirlos a toda costa en empresarios, y en nombre de la modernización someterlos a la economía formal, se limitan los apoyos oficiales, aumenta la informalidad

\footnotetext{
${ }^{2}$ Por ejemplo, en el Sistema de Administración Tributaria (SAT), no existe una categoría de contribuyente específica para los productores artesanos, sólo está la de productor primario y la de transformador; esta última es concebida para industriales, pero la aplican de igual manera - con las mismas obligaciones - a los productores de alimentos, bebidas, medicamentos, etc., procesados artesanalmente, al inscribirlos en el Sistema.

${ }^{3} \mathrm{El}$ patrimonio biocultural se define como "los saberes culturales sobre la riqueza biológica y los potenciales ecológicos de la región” (Leff, 2009: 11).
} 
y se llega a la aberración de volver clandestinos los procesos y productos artesanales. De esa manera, los artesanos y comerciantes de artesanías, con tan sólo la creación o modificación de una Norma Oficial, pueden llegar a ser catalogados como infractores e incluso caer en la categoría de delincuentes.

De hecho esto ya está ocurriendo, por ejemplo, con los productores de quesos artesanales: debido a la reforma de la Norma Oficial Mexicana (NOM) 243, la cual obliga a pasteurizar la leche con la que se hará queso, el que no cumpla dicha disposición cae oficialmente en la clandestinidad. Otro ejemplo lo encontramos con los destiladores de agave que están fuera de las Denominaciones de Origen - tequila, mezcal y sotol - con la NOM 199, en la cual se pretende obligar a los destiladores tradicionales de agave a llamar a su producto con el desconocido y vacío nombre de "Komil" (Hernández, 2016: 20-23), a bajar la calidad del producto - que no sea ya $100 \%$ agave, sino que sólo contenga $51 \%$ - y poner en la etiqueta los ingredientes con los cuales se rebaja ese porcentaje de agave; mientras que los proponentes de esas reformas — encabezados por los de la industria del tequila — no se ven obligados a ofrecer dicha información al consumidor.

Otro ejemplo es la reforma fiscal, en la que el productor artesano - el que transforma materia prima en un producto u objeto mediante un proceso artesanal—, no tiene una categoría específica — como sí la tiene un productor primario- en el Sistema de Administración Tributaria (SAT); por lo que el registro ante el SAT del productor artesanal sólo puede hacerse con la categoría de transformador, la cual, sin reparar en sus abismales diferencias, le implica las mismas obligaciones que dicho Sistema le impone a los industriales.

Un intento de responder a ese mecanismo perverso, operado por grandes empresas en contubernio con instituciones oficiales, es la generación de procesos de activación de los patrimonios culturales, específicamente aquellos que están en mayor vulnerabilidad, como son los constituidos por productos alimenticios procesados artesanalmente, y demostrar así que dichos productos tienen particularidades y oportunidades que los marcos normativos e institucionales vigentes socaban, lejos de tomarlas en cuenta. 
La activación socio institucional de procesos de revaloración cultural y económica de los productos artesanales, como el llevado a cabo en el caso del queso Cotija, es una vía que tiene como expectativa un tipo de desarrollo específico (Barragán, 2003), adecuado para cada grupo cultural y su propio medio geográfico, desde luego, en interacción con otros lugares y culturas. Éste, también llamado "proceso de patrimonialización” (Linck, Navarro y Barragán, 2014: 70), puede iniciar con la generación y sistematización de conocimientos — normalmente por parte de la academia - en torno al producto artesanal de más alta densidad cultural en cada lugar, comunidad o región.

Un producto de alta densidad cultural es aquel que representa, para propios y extraños, un referente identitario, debido a que condensa - y en torno al cual gira - todo un sistema de producción y reproducción social y económica específico — cosmovisión—, alimentado por hondas raíces históricas con fuerte anclaje a un territorio determinado culturalmente (Barragán y Ovando, 2015).

El reconocimiento que puedan tener esos productos de alta densidad cultural por parte de propios y extraños, e incluso por parte de la academia y de instancias oficiales nacionales e internacionales, es apenas el primer paso para iniciar el proceso de activación socio institucional, al cual remite rápidamente tanto la constitución de asociaciones - personas morales, empresariales o civiles- como las diversas figuras de protección legal de sus productos, medios y espacios de producción y de vida.

\section{Las oportunidades para productos alimenticios obtenidos artesanalmente: IG, DO y MC}

Parala revaloración y protección oficial de dichos productos, de sus procesos de producción y de sus entornos culturales y ambientales, en México se puede recurrir a las siguientes figuras: Indicación Geográfica (IG), Denominación de Origen (DO), y Marca Colectiva (MC), mecanismos previstos por el mismo modelo de desarrollo económico imperante para salvaguardar — teóricamente- la diversidad de tradiciones y de vías de desarrollo. Por Indicación Geográfica (IG) se entiende un signo utilizado para productos que tienen un origen geográfico concreto y cuyas 
cualidades, reputación y características se deben esencialmente a dicho origen. Los elementos constitutivos de las indicaciones geográficas son: producto diferenciado por su origen geográfico concreto, con cualidades, reputación y características determinadas por el origen.

En el mismo orden de ideas, las DO son un tipo especial de Indicación Geográfica en la que el producto toma la denominación geográfica de un país, de una región o de una localidad que sirva para designar un producto originario del mismo y cuya calidad o características se deben exclusiva o esencialmente al medio geográfico, comprendidos en éste los factores naturales y los factores humanos. ${ }^{4}$ Por su parte, la MC es un signo distintivo para identificar productos elaborados y/o servicios prestados por agrupamientos de emprendedores de la Economía Social. Representa los valores del trabajo asociativo, identidades locales, métodos productivos comunes y estándares compartidos para cada uno de los productos.

El objetivo principal de esta herramienta consiste en fortalecer la producción y la comercialización de los emprendimientos, otorgándoles valor agregado y mayor visibilidad, además de garantizar su calidad. Por otra parte, promueve el compromiso social, fomentando el comercio justo y el consumo responsable. ${ }^{5}$

Algunos posibles beneficios de estas figuras de protección legal, vistas como oportunidades para los productos procesados artesanalmente y para las formas de vida que les dan soporte, se mencionan a continuación:

- Indicación Geográfica (IG), Denominación de Origen (DO) y Marca Colectiva (MC), son un fuerte instrumento de desarrollo sostenible para los productores locales y las comunidades, al permitir, favorecer y fomentar la continuidad cultural — transmisión del conocimiento de generación en generación-y el arraigo territorial de las poblaciones.

- Dan valor agregado a los productos protegidos ya que éstos son revalorados por los consumidores y se diferencian de los productos

\footnotetext{
${ }^{4}$ Véase http://www.inapi.cl/portal/institucional/600/w3-article-750.html [consultado el 30 de abril de 2016].

${ }^{5}$ Véase http://www.desarrollosocial.gob.ar/buentrato/3587 [consultado el 20 de mayo de 2015].
} 
altamente industrializados — con aditivos— respecto a la calidad y a la certeza del origen.

- Conservan su esencia derivada de la relación con la tierra de origen o los elementos técnicos y/o procesos de manufactura derivados de añejas tradiciones en cada comunidad, pueblo y región. - Garantizan al consumidor el adquirir un producto original en sus componentes y origen.

- Dan una oportunidad de comercialización basada en el comercio ético, justo y responsable, así como de posicionarse en mercados específicos que vienen en ascenso en México y en otros países. - Mejoran los precios de los productos obtenidos mediante procesos tradicionales que representan la objetivación del patrimonio cultural y el prestigio social de quienes los producen.

- Recuperan el orgullo de las familias y la dignidad de los pueblos por sus productos, valores y tradiciones.

- Aligeran el impacto negativo al medio ambiente, ya que en el proceso productivo se utilizan ecotecnias que son más blandas y sostenibles en comparación con la tecnología industrial.

- Favorecen un tipo de desarrollo territorial y humano basado en la continuidad cultural de cada pueblo, y ejercen una menor presión sobre los recursos naturales de su entorno.

A pesar de todas las ventajas y beneficios de estas figuras, que podemos considerar claramente como oportunidades para el desarrollo territorial y de los productos artesanales, al echar a andar los procesos de patrimonialización, bajo esta lógica de protección legal, de los productos de alta densidad cultural para su desplazamiento en el marco de la economía popular (Linck, Moguel y Ramírez, 2011), van saltando los obstáculos y limitaciones socioinstitucionales que, en la práctica, tienden a desvirtuar dichos procesos e incluso a poner en mayor riesgo de deterioro los patrimonios que se pretende salvaguardar. ${ }^{6}$

\footnotetext{
${ }^{6}$ Con todo, es importante seguir avanzando en la generación de conocimientos, de debates, de propuestas y acuerdos que den pie al desencadenamiento de procesos que en principio atajen la destrucción y al final logren la revitalización de los diversos patrimonios culturales que aún se mantienen en cada pueblo.
} 
El esbozo de los obstáculos que podemos vislumbrar en estos procesos, a nivel de los productores artesanos para su organización y conversión a "empresarios", de las instituciones tanto gubernamentales, por sus marcos legales, burocracias y normatividades, como académicas, con sus propuestas de cambio técnico aparentemente neutro, y de los mercados, puede ayudar a encontrar maneras de franquear los grandes abismos que encontramos entre los dos mundos, con sus respectivos modelos de producción y cosmovisión: el campesino-artesanal en un extremo y el empresario industrial en el otro, en medio hay una gama muy amplia de actores. Ambos extremos se encuentran intervenidos, de manera muy desigual y desequilibrada, por las normatividades y orientaciones institucionales y empresariales.

La problemática planteada se ilustra mediante la experiencia alcanzada en el proceso de patrimonialización echado a andar desde finales del siglo pasado (Barragán y Ovando, 2015) en torno a la revaloración cultural y económica del queso Cotija, proceso nucleado por la búsqueda de una Denominación de Origen.

\section{El proceso de patrimonialización del queso Cotija artesanal: una carrera de obstáculos}

La tradición del queso Cotija se remonta, en el tiempo, a los principios de la colonia y, en el espacio, a las sierras de ocupación mestiza o ranchera del occidente de México. De aquellos lejanos tiempos y vastos lugares, la tradición se vino disolviendo hasta sólo quedar resguardada en el presente por unas 200 familias que se refugian en igual número de ranchos - minúsculos asentamientos humanos-, aislados y dispersos, entre los pliegues de la sierra donde confluyen los estados de Jalisco y Michoacán — Sierra de Jalmich (Cf. Barragán, 2010). 
Mapa: Sierra de Jalmich, región de origen del queso Cotija.

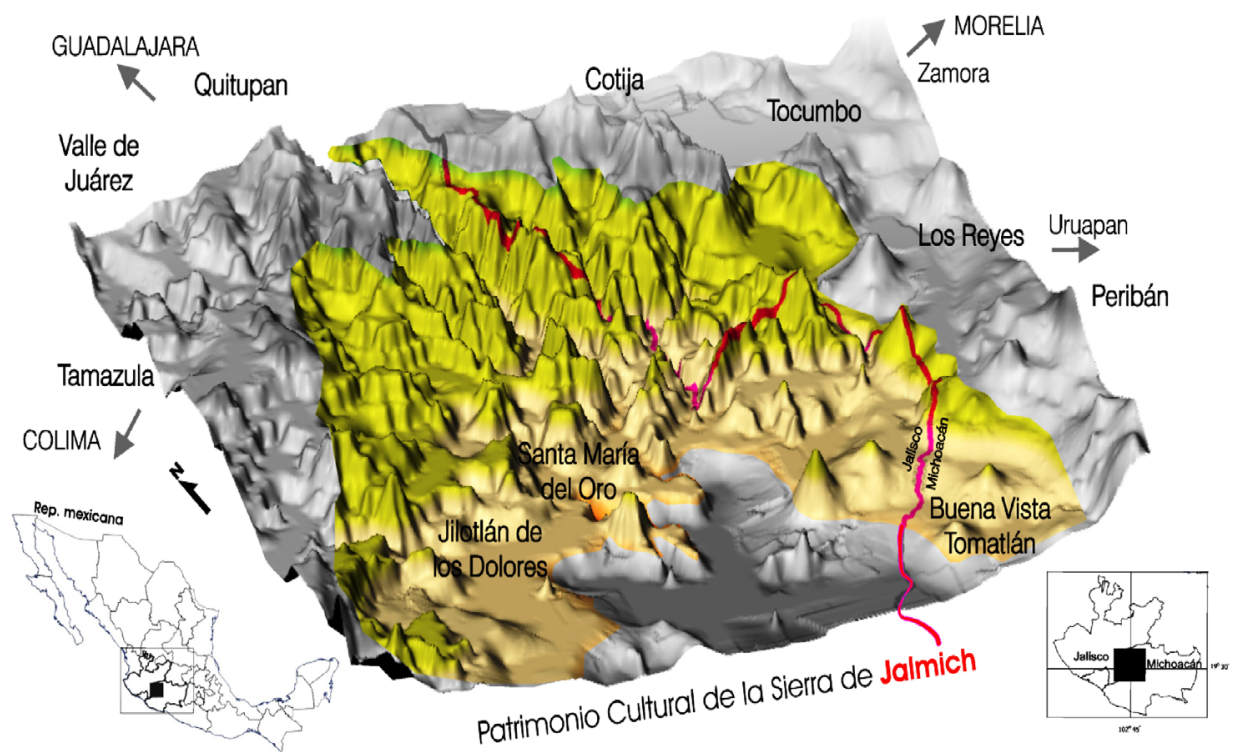

Conforme transcurría la segunda mitad del siglo pasado, aún en este último bastión serrano de producción del queso Cotija, la tendencia a su desaparición parecía inminente. De los aproximadamente 900 ranchos de ordeña diseminados en dicha región, donde se producían anualmente alrededor de mil toneladas de queso en los ańos cincuenta, el número de ranchos y de toneladas habían descendido tres cuartas partes - 225 ranchos, 250 toneladas - para finales del siglo XX (Barragán y Chávez, 1998).

Lo más significativo era que dicha tendencia se acentuaba drásticamente y, que de seguir su curso estadístico, en el año 2010 se terminaría la producción del auténtico queso Cotija; es decir, el queso artesanal, madurado, producido únicamente durante la temporada de lluvias de cada ańo en los ranchos de la ignota sierra de Jalisco-Michoacán.

Ante este escenario y con la intención de revertir la tendencia mencionada, desde 1998 se fueron conjuntando esfuerzos de académicos, productores y autoridades de los tres órdenes de gobierno, hasta echar a andar — en el año 2001 — el proyecto titulado "La potencialización del 
patrimonio cultural en la sierra de Jalisco-Michoacán”. Como objetivo general se planteó contribuir al fomento y revaloración del patrimonio cultural heredado por los habitantes de los ranchos de la región, impulsando y acompañando el proceso social, organizativo, tecnológico, legal y comercial, necesario para lograr la denominación de origen del queso Cotija y, mediante dicha denominación, un desarrollo regional integral (Barragán, 2003).

En este proceso aparece la gran complejidad y cantidad de obstáculos sociales, institucionales y del mercado que hay que enfrentar cuando se pretende proteger, revalorar y revitalizar el patrimonio cultural de los pueblos como base de su desarrollo.

El histórico individualismo atribuido a los rancheros inicialmente fue vencido por la amenaza de un enemigo común: la industria quesera, y algunos productores artesanales de otras regiones que venían usurpado el nombre de queso Cotija para ponerlo a sus quesos frescos y análogos que en ocasiones ni leche contienen, con lo cual logran bajar los costos, ganar mercado y sacar de la competencia a los productores del queso genuino. La puesta en común de esta situación alentó la unión de los productores de la sierra, quienes apoyados por investigadores y autoridades locales lograron constituirse en la figura legal de Sociedad de Producción Rural (SPR), misma que inició con ocho miembros en el año 2001 e incorporó a otros 82 productores en 2004.

Dadas las dificultades físicas — dispersión y aislamiento-, materiales — falta de recursos económicos_-, administrativas — región repartida en dos entidades y varios municipios que operan sin coordinación-, y culturales — convocar reuniones, realizar gestiones, enfrentar la competencia desleal, lograr acuerdos y darles seguimiento-, la organización ha desempeñado un papel más de legalidad que de funcionalidad. Con todo, en el año 2005 dicha SPR obtuvo del Instituto Mexicano de la Propiedad Industrial (IMPI), para su queso, la Marca Colectiva Cotija Región de Origen; por cierto, la primera Marca Colectiva que otorgó ese Instituto a un producto alimenticio procesado artesanalmente en México.

Con la gran difusión en ferias y otros medios de promoción y comunicación, paulatinamente se ha venido logrando revalorar 
la actividad y aumentar el precio de este queso. Sin embargo, la organización de los productores es una batalla a la que aún le falta mucha estrategia y constancia. La batalla en este frente ha sido y seguirá siendo permanente e incierta.

Pese al impulso que desde el inicio algunas instituciones académicas y gubernamentales — más precisamente de su personal— le han dado a este proceso, son constantes y muy cuesta arriba las situaciones en este campo, primero para atraer la atención de dichas instituciones y poner el proceso en el radar de sus intereses; segundo, para tratar de evitar que este caso sea tomado por los “arribistas” como botín político, económico y hasta académico.

Una de las primeras batallas malogradas fue cuando IMPI, sin mayores argumentos, le otorgó a la SPR una Marca Colectiva en lugar de la Denominación de Origen solicitada para el queso Cotija. El hecho ha destapado una serie de limitaciones institucionales y legales, entre las que destaca la imposibilidad de IMPI para acuerpar los productos a los que les otorga una Marca Colectiva, dado que ésta sólo protege un logotipo — signo distintivo o nominación no tradicional—y no el nombre común del producto ni del lugar de origen (LPI, 1991). ${ }^{7}$

Esta imposibilidad se deriva de la Ley de la Propiedad Industrial, en la cual sólo la Denominación de Origen —y ninguna otra figura de las contenidas en dicha Ley- protege el nombre del producto y del lugar de producción, tal como sí lo hacen en otros países diversas figuras —v. g., la de Indicación Geográfica-. Por lo tanto, se hace patente la necesidad de actualizar el marco legislativo e institucional que nos rige en esta materia de la propiedad, ya que sólo está dirigida a ver por las actividades industriales y comerciales, y deja desprotegida la actividad y los productos artesanales, que a todas luces son propiedad intelectual de los artesanos. Al no contar éstos con protección específica, sus objetos y productos están expuestos a la piratería por parte de industrias y a la creación de error o confusión entre los consumidores respecto a la calidad y procedencia de esos objetos y productos artesanales.

\footnotetext{
${ }^{7}$ Sin embargo, tal como se otorgó esta MC —y las que le siguieron en Michoacán—, remite más a una Indicación Geográfica que a una MC, lo cual es un caso inédito e interesante dado que favorece la protección del producto y del territorio de procedencia, como se analizará más adelante.
} 
En cuanto a la comercialización, el camino es lento. Tener la marca para distinguir el producto en el mercado es un gran avance; sin embargo, las dificultades inician al momento en el que los productores la quieren usar; IMPI otorga la Marca pero después no se sabe cómo usarla, y si no se usa en los primeros tres ańos, se cancela.

Se debe constituir un comité de autorregulación y en definitiva entrar a la economía formal, que más que un canal legalmente constituido, es para los productores un verdadero laberinto sin salida. Además de los problemas legales — registro en SHCP, capacitaciones, facturación, etiquetado, muestreos, certificaciones, verificaciones, actualizaciones, etc.- - al lado de los mismos aparecen los laberintos comerciales.

Al buscar nuevos nichos de mercado se cae en los extremos de demanda: muy pequeña, lejana y esporádica; o tan grande y exigente en requisitos que no se tiene la capacidad de responder en cantidad, condiciones y periodicidad como es requerida, de tal manera que el acceso a nuevos nichos de mercado — sean solidarios o no- es muy accidentado y lleno de riesgos para los pequeños productores y microempresarios. Les queda continuar en el mercado tradicional en el que los acaparadores regionales los tienen también castigados. Esto se conjuga con la incapacidad financiera y administrativa para lograr el acopio, lo perecedero del producto y las formas de operar tanto de los acaparadores locales como de las grandes cadenas comerciales que buscan el más bajo precio y riesgo, así como el más largo plazo para pagar y hasta pretextos para no hacerlo por completo.

Particularmente es problemático entrar a los supermercados debido a la maraña de normas que aplican: unas impuestas por el fisco y demás dependencias gubernamentales, como las asociadas a la facturación y a las incontables, cambiantes y amañadas —en favor de la industriaNormas Oficiales Mexicanas (NOM) de producción, de salud, de etiquetado, etcétera.

Otras normas son impuestas por las propias empresas para su comodidad y ahorro de dinero y de tiempo, como contratos ventajosos para ellas, uso de código de barras, horarios de atención a proveedores, condiciones de recepción de mercancía y de pagos, así como disposiciones de venta, acomodos de mercancía, comisiones, descuentos 
y devoluciones. Los grandes supermercados sólo ponen el espacio y es el proveedor quien debe hacerse cargo de la promoción, acomodo físico, pedidos, cobranza, devoluciones, batalla con la competencia, entre otros.

Todo lo anterior inhibe al sector artesanal el acceso a estos importantes canales de comercialización. Particularmente son prohibitivos para los productos alimenticios artesanales, aun para aquellos que, como el queso Cotija, cuentan con una $\mathrm{MC}$ y han avanzado en el proceso de inserción a la economía formal y en el desarrollo empresarial al que conduce ese proceso.

El impasse mayor lo constituye la Secretaría de Hacienda y Crédito Público (SHCP), toda vez que el Servicio de Administración Tributaria (SAT) no tiene una categoría de contribuyente que acomode al artesano, también por un vacío - ¿voluntario?- en las leyes. De ahí que si los productores de queso Cotija artesanal - al igual que otros artesanos que transforman materia prima en la elaboración de sus productos-, deciden darse de alta en Hacienda, dado que transforman la leche en queso, son considerados como industriales, por tanto, tratados como cualquiera de las grandes empresas de productos lácteos, con todas las consecuencias que eso implica en administración, facturación y contabilidad electrónica, nómina, carga fiscal, cuenta de cheques, clave bancaria para las declaraciones por Internet. Todo ello cuando $90 \%$ de productores del queso Cotija de la MC no cuenta con energía eléctrica, menos con computadora ni cobertura de Internet, y generalmente sólo realizan una venta de queso al año.

En medio de este incierto panorama, con un sin número de batallas pasadas, presentes y futuras, unas bien libradas, otras perdidas, pero en la mayoría de ellas aún con el ánimo de resistir, ahora las autoridades "competentes" proyectan — seguramente en contubernio con otros no muy competentes-, sacar para siempre del escenario a los productores de quesos artesanales, como lo del queso Cotija.

\section{La construcción oficial de la clandestinidad}

El intento de dar el "tiro de gracia" a estos quesos artesanales ${ }^{8}$ estuvo

${ }^{8}$ En un interesante libro, que en 2009 ganó el primer lugar mundial de los libros sobre quesos, otoño-invierno 2016 
plasmado en la Norma Oficial Mexicana 243 (NOM-243-SSA12010), ${ }^{9}$ en cuya modificación del año 2011 se establece que en México sólo se podrá hacer queso con leche sometida a tratamientos térmicos, pasteurizada, y en el caso de quesos madurados — como el Cotija—, deben cumplir con el Sistema de Análisis de Peligros y de Puntos Críticos de Control (HACCP). Esta disposición no puede cumplirse en las condiciones de marginalidad y precariedad en la que se encuentran los ranchos productores de queso y que, de intentarlo, los volverían insoportablemente dependientes de procedimientos administrativos, tecnocráticos y burocráticos, que atentarían contra la tipicidad, calidad e incluso permanencia en la producción del mismo queso.

Disposiciones - reformas - como éstas borran todos los esfuerzos socioinstitucionales que previamente se lograron alinear para construir primero las Reglas de Uso de la Marca Colectiva del queso Cotija ${ }^{10}$ registradas ante el IMPI, 2005, y después, la Norma Mexicana Específica para el queso Cotija Artesanal Madurado (NMX-F-735COFOCALEC-2011). La Norma que fue construida por más de 20 instituciones a lo largo de un año de reuniones mensuales en el Consejo de Fomento a la Calidad de la Leche (Cofocalec). Asimismo derogaron otra norma y reglamento en los cuales estaba permitido elaborar queso con leche cruda, siempre y cuando dicha leche proviniera de hatos libres de brucelosis y de tuberculosis y que el queso fuera madurado al menos 30 días. De hecho, en dicha NOM se ponía como ejemplo de queso madurado al queso Cotija — antes de que tuviera la MC y antes de la reforma.

En las Reglas de Uso de la Marca Colectiva del queso Cotija y en la Norma Mexicana específica (NMX-F-735), siguiendo la costumbre y con la participación de los productores, se estableció que una pieza de queso no puede partirse antes de los 90 días de maduración. Esto se

se presentan muy adecuadamente unos 30 diferentes quesos elaborados artesanalmente, de entre todos los que todavía se producen en distintas regiones del país. Fernando Cervantes, Abraham Villegas, Alfredo Cesín y Angélica Espinoza, Los quesos mexicanos genuinos. Patrimonio cultural que debe rescatarse. México, MPM/UACh/UAEM, 2008, 186 p.

9 Véase, www.cofocalec.org.mx/catalogo/por_clave; www.canilec.org.mx/Circulares2011/ DECLARATORIA de vigencia

${ }^{10}$ Álvarez, Barragán y Chombo, 2005. 
cumple para el queso comercializado con la Marca Colectiva sólo en el Centro de Acopio - Mesón del Queso Cotija, SRL de CV, creado en 2008 - ${ }^{11}$. Sin embargo, en cuanto se logró cumplir una disposición, apareció otra que vuelve a dejar al queso - y a otros productos artesanales- "fuera de Norma", como es el caso de la facturación y la contabilidad electrónica, el semáforo calórico que debe incluirse en la etiqueta, por mencionar las más recientes.

El argumento de la Comisión Federal para la Protección Contra Riesgos Sanitarios (Cofepris) para hacer dicha prohibición -uso de leche cruda en la elaboración de queso- es que en el país hay entidades con alta incidencia de brucelosis y de tuberculosis en el ganado, lo que de hecho es cierto. Sin embargo, cuando se logró introducir la campaña de detección de dichas enfermedades en la región productora del queso Cotija, la incidencia no llegó ni a $1 \%$ y la prevalencia fue cero; ${ }^{12}$ lo que significa que los pocos animales que han dado positivo en la muestra, invariable e inmediatamente fueron sacados de los ranchos y enviados al rastro, tal como lo establece el procedimiento legal en esos casos. Pese a lo anterior, algunos ranchos fueron puestos en cuarentena por parte de la Sagarpa y, aun cuando los animales que dieron positivo fueron sacados de los ranchos, ya no tuvo capacidad o voluntad para quitar la cuarentena a dichos ranchos, pese a los muestreos subsecuentes que dieron negativo.

Por otra parte, el conocimiento científico ha confirmado la seguridad sanitaria — inocuidad - que alcanza este queso de leche cruda gracias al medio ambiente, a las técnicas tradicionales y al proceso de maduración que lo caracteriza: “... la maduración del queso Cotija, así como de otros quesos artesanales, depende de las bacterias y de las levaduras que existan en su ambiente, esto es, aquellos que están en los ingredientes y en los instrumentos con que se elaboran o en las manos de los individuos que intervienen en su fabricación" (Cevallos, 2015). $\mathrm{Al}$ respecto ya se cuenta con profundos estudios que avalan y explican

\footnotetext{
${ }^{11}$ El Mesón del Queso creado en diciembre de 2006 de manera informal con cinco socios, se formalizó en 2008 como SRL de CV con nueve socios, y se reestructuró en 2011 con el ingreso de 20 productores y la salida de tres viejos socios, quedando finalmente 26 socios.

${ }^{12}$ Datos obtenidos del Subcomité de Bovinos de la Dirección de Ganadería del Gobierno del Estado de Michoacán, Sedagro, San José de Gracia, Mich., 2011.
} 
científicamente la inocuidad del queso Cotija artesanal madurado, sin necesidad de pasteurizar la leche con la que se elabora en los ranchos de la región de origen. Además de los estudios pioneros de Patricia Chombo Morales, del Centro de Investigación y Asistencia en Tecnología y Diseño de Estado de Jalisco (Ciatej):

Algunos investigadores del Centro de Biotecnología Genómica y de la Escuela Nacional de Ciencias Biológicas, ambos del Instituto Politécnico Nacional, han estudiado la microbiología del queso Cotija y determinaron que en él habitan levaduras de los géneros Kluyveromyces, Pichia, Rhodotorula, y Galactomyces, y también bacterias lácticas de los géneros Pediococcus y Lactobacillus. Además, comprobaron la presencia de algunas bacterias de los géneros Weissella y Tetragenococcus, que toleran o de plano gustan de los ambientes salados, lo cual no es de extrańar, ya que el queso Cotija contiene una importante cantidad de sal (Cevallos, 2015).

Más recientemente y con técnicas muy sofisticadas,

La Dra. Maricarmen Quirasco y su alumna Alejandra Escobar (FQUNAM), en colaboración con el Dr. Alejandro Sánchez (IBT-UNAM), a fin de resolver de una vez por todas el problema, decidieron aplicar técnicas de metagenómica; acercamiento experimental que consiste en purificar el ADN presente en una muestra ambiental, determinar su secuencia con las nuevas plataformas de secuenciación masiva y con esta información identificar las bacterias que ahí viven y dilucidar qué es lo que hacen. Para ello, la Dra. Quirasco y su equipo colectaron quesos Cotija de la Sierra de Jalmich, aislaron y secuenciaron el ADN ahí presente con un instrumento de última generación llamado Hiseq. Gracias a este esfuerzo colectaron una enorme cantidad de datos que equivaldría a tener la secuencia completa del genoma de 7 personas. Interpretarlos exigió muchas horas de trabajo y el uso de sofisticados programas bioinformáticos. Los resultados fueron asombrosos, ya que se pudieron identificar 574 géneros bacterianos, muchos más de los que se identificaron con otras técnicas. Entre estos géneros, los más 
importantes fueron Lactobacillus (8 especies), Weissella (2 especies) y Leuconostoc (4 especies). Las bacterias no sólo proporcionan sabor al queso, sino como me dijo en entrevista la Dra. Quirasco: “... en la microbiota nativa [del queso Cotija] existen microorganismos que producen enzimas con actividad lítica contra patógenos, como Listeria, Staphyloccocus y E. coli, que contribuyen a la inocuidad del producto. Con el análisis de los datos se identificó todos los genes relacionados con la producción de las substancias que le dan su sabor al queso Cotija” (Cevallos, 2015).

Aun con estos importantes avances en el conocimiento científico sobre la inocuidad del queso Cotija, ${ }^{13}$ derivada de su elaboración artesanal, que es lo que se defiende en el proceso de patrimonialización, sigue vigente la amenaza de aplicación de una normatividad que amenaza su producción bajo el sistema tradicional. Esto evidencia que en las reformas a la NOM, lo menos que se busca es la seguridad sanitaria, la legalidad y el bien común — la salud pública — alardeado en los discursos y exposición de motivos en los que se pretenden justificar los cambios legislativos y la normatividad sanitaria.

A todas luces, con dichas reformas se busca favorecer a ciertos sectores a costa de los intereses y de las raquíticas economías de los pequeños productores artesanales. Si la intención oficial que predomina - inducida por los intereses de empresas transnacionales- fuera congruente con sus discursos, se apoyaría con inversión pública a las unidades de producción agropecuaria de donde salen los quesos artesanales, se simplificarían y adecuarían los trámites y apoyo en: sanear los hatos de los pequeños productores, mejorar la infraestructura básica y productiva en las regiones ganaderas tradicionales, facilitar el intercambio de conocimientos entre productores y de éstos con la academia - no en la capacitación tan puesta de moda como inapropiada-, sobre las buenas y malas prácticas de manufactura que cada uno de esos actores conoce; y finalmente habría que invertir también en facilitar $-\mathrm{O}$ al

\footnotetext{
${ }^{13}$ Los hallazgos más recientes y sorprendentes han sido ya publicados por el Conacyt, como la investigación ganadora en la Categoría Profesional de Ciencia de Alimentos, en el Premio Nacional de Tecnología de Alimentos 2016. http://www.pnctacocacola.com.mx/ (Escobar, Quirasco y Sánchez, 2016).
} 
menos en no obstaculizar con normas inaplicables- el acceso a los mercados, bajo principios de la economía social.

Todo lo anterior y mucho más podría hacerse en lugar de seguir construyendo su clandestinidad mediante normas improcedentes, que sólo vuelven más cuesta arriba el camino a los sectores ya de por sí vulnerables, sin eliminar de raíz las causas que los han puesto en tal situación. En suma, el proceso de revitalización del patrimonio cultural y desarrollo territorial que se ha impulsado socioinstitucionalmente en torno a la protección legal del auténtico queso Cotija, producto emblemático de una región y de una cultura, ha enfrentado muchos retos. En este sentido, hacen falta abrir muchos debates, lograr algunos acuerdos y, sobre todo, compromisos. También muestra que las instituciones, sus marcos normativos, políticas, programas, proyectos y voluntades, están lejos de atender las necesidades y realidades que enfrenta cotidianamente la mayoría de los pequeños productores artesanales en México.

\section{¿A qué intereses están respondiendo nuestras instituciones?}

Tal como se están dando las cosas con el marco legal e institucional que nos rige, lejos de estar acercándonos a la protección legal de los productos que representan el patrimonio cultural de los diversos pueblos de México, se está favoreciendo la proliferación de productos adulterados, de imitación y, en fin, de los productos "piratas", toda vez que a los auténticos, aun con la Marca Colectiva que se les otorga, no se les puede autorizar ni garantizar exclusividad, ni siquiera en el nombre con el que son conocidos tradicionalmente y respetados en sus propios lugares de producción; es decir, no se protege su nombre ni su origen de las imitaciones que aparecen por todas partes con la complicidad de las autoridades que, de acuerdo con la ley, deben combatir la piratería.

Las Marcas Colectivas, tal como están siendo concebidas en México, no protegen los nombres de los productos ni de los lugares y procesos de producción a los que están histórica, cultural y geográficamente anclados. Estos elementos que representan nada menos que los principales componentes de los patrimonios de los pueblos, en los 
cuales pueden fincar, mejor que en ningún otro, un desarrollo propio, es decir, aquel que favorezca la continuidad cultural de cada pueblo.

Sabemos que una protección cabal de los productos vinculados a su territorio sólo se puede hacer con Indicación Geográfica - que no existe en la Ley de Propiedad Industrial, pero sí en los convenios y acuerdos internacionales, incluido el TLCAN, firmados por nuestro país - o más aún con una Denominación de Origen; figura jurídica que IMPI no se decidió a otorgar a los productos alimenticios procesados artesanalmente, como lo ejemplificamos con el queso Cotija que fue el primero en solicitar una DO desde el año $2004 .{ }^{14}$

Tanto por vacíos en la ley, como la carencia de categoría de Indicación Geográfica que permita ligar el producto a su territorio y a la cultura que lo sostiene en cualquiera de las figuras legales de protección, y su reduccionismo a productos industriales en un país caracterizado por un claro predominio de la actividad primaria - principalmente agropecuaria - y artesanal, como por la interpretación que de la Ley de la Propiedad Industrial (LPI) han hecho funcionarios del IMPI en detrimento de la protección y permanencia de los productos auténticos o genuinos; se están favoreciendo, por un lado las imitaciones, falsificaciones y piratería en general, y por el otro a las industrias y empresas transnacionales. Lo anterior con el beneplácito y hasta complicidad de ciertas autoridades que no aplican la Ley —en este caso la Ley de Propiedad Industrial—, como a continuación podemos ilustrar en el caso de la piratería de la que está siendo objeto el queso de la Marca Colectiva Cotija Región de Origen.

La Ley de la Propiedad Industrial (LPI), en su artículo 213, fracciones IV, V, VIII, XIX, XXI y XXVI, considera y establece sanciones que las autoridades hasta ahora no aplican, como infracciones administrativas:

\footnotetext{
${ }^{14}$ Esta negativa significó un lamentable rezago en la protección de alimentos artesanales por parte de las autoridades mexicanas; rezago que se sigue ensanchando sin que México tome medidas para enmendarlo, mientras otros países ya las empiezan a tomar: el gobierno de Costa Rica se decidió a otorgar la DO al queso Turrialba en 2014, primera DO que se otorga en el continente americano a un queso, cuyos atributos no son mayores a los presentados diez años antes en México en el expediente de solicitud de DO al queso Cotija ante IMPI.
} 
... actos que causen o induzcan al público a confusión, error o engaño, por hacer creer o suponer infundadamente que el producto de que se trate proviene de un territorio, región o localidad distinta al verdadero lugar de origen, de modo que induzca al público a error en cuanto al origen geográfico del producto.

Asimismo, tipifica como delito, en su artículo 223, Fracc. II, "Falsificar, en forma dolosa y con fin de especulación comercial, marcas protegidas por esta Ley".

Con todo, desde hace muchos años, y sobre todo después de haber obtenido, amparado y distinguido a este queso con la denominación Cotija Región de Origen desde el año 2005 — renovada en 2013 - y pese a las disposiciones contenidas en la Ley de la Propiedad Industrial y en la Ley de la Protección al Consumidor, el nombre de queso Cotija, y ahora de toda la Marca Colectiva Cotija Región de Origen y diseño, se utiliza total o parcialmente, junto con otros emblemas - como el de haber sido este queso el ganador del primer lugar en el campeonato mundial de quesos de calidad en Italia, 2006 - , de manera totalmente ilegítima e ilegal por productores, industriales, empresas y comercializadores ajenos a los derechos de uso exclusivo de nombre y territorio que sólo corresponde a los titulares de la denominación Cotija Región de Origen, con la cual está amparado legalmente este queso.

De acuerdo a la LPI, a ningún otro queso se le puede denominar Cotija, debido a que esta palabra es parte de la denominación y signo reservado a esa Marca Colectiva. En otras palabras, lo que IMPI otorgó al queso Cotija fue más que una Marca Colectiva; de hecho y de derecho, aunque sin explicitarlo — por no percatarse o por no comprometerse, pero en cualquier caso se le agradece-, le otorgó una Indicación Geográfica, toda vez que la Marca es Cotija Región de Origen - aun cuando una marca no puede contener el nombre de un lugar-; al contener la palabra "Cotija", ésta remite a un lugar o referente geográfico, y las otras palabras, "Región de Origen”, explicitan que dicho lugar abarca el espacio geográfico regional — sierra de Jalmich con delimitación cartográfica en el expediente que obra en IMPI-, en el cual se encuentra justamente el origen o procedencia del producto 
que protege dicha expresión. Este asunto no es trivial, al contrario: representa el sustento legal para la protección oficial del queso, la cual no ha ocurrido.

Antes, pero sobre todo después de la obtención de la MC y aún más actualmente, han surgido varias imitaciones del queso Cotija, varios quesos tipo Cotija. Se produce en distintos lugares del país - y de EEUU- y también en los alrededores de la zona delimitada como el actual reducto o refugio geográfico y cultural —región — donde persisten las prácticas productivas artesanales de antaño — Sierra de Jalmich—. También se produce queso tipo Cotija en varios estados, principalmente en Jalisco - fuera de la región de origen—, Veracruz y Chiapas; incluso algunos de esos quesos no usan en su etiqueta ni la leyenda "tipo Cotija”, sino abiertamente le ponen en su etiqueta Queso Cotija, como lo hacen, entre otros, Esmeralda, El Ciervo, La V de Mu y Frankly; y así aparece donde lo comercializan: en las tiendas de las principales cadenas de supermercados, como Wal ${ }^{*}$ Mar, Soriana, Comercial Mexicana, Bodega Aurrerá, e incluso Costco.

El caso más emblemático para ejemplificar el descaro con el que se infringe la ley por parte de grandes productores, comercializadores y autoridades, es el del queso que se anuncia en su etiqueta como: "Queso Cotija Chiapaneco Flankly". Evidentemente que con dicho nombre se está incurriendo en infracciones administrativas establecidas claramente en el Art. 213 de la Ley de Propiedad Industrial, que a la letra dice:

Son infracciones administrativas:

IV.- Usar una marca parecida en grado de confusión a otra registrada, para amparar los mismos o similares productos o servicios que los protegidos por la registrada;

IX.- Efectuar ... actos que causen o induzcan al público a confusión, error o engańo, por hacer creer o suponer infundadamente:

d) Que el producto de que se trate proviene de un territorio, región o localidad distinta al verdadero lugar de origen, de modo que induzca al público a error en cuanto al origen geográfico del producto. 
El caso no termina aquí, pues de acuerdo con el artículo 223 de la misma ley (LPI), varias de estas prácticas están tipificadas como delitos que se deben perseguir de oficio y aplicar sanciones a los infractores; sin embargo, se produce, transporta, almacena y vende queso llamado Cotija, a todas luces falsificado, en establecimientos comerciales, de manera organizada y permanente durante varios años, y no se ha procedido de acuerdo con estas disposiciones.

El mencionado artículo 223 de LPI establece que son delitos:

III. Producir, almacenar, transportar, introducir al país, distribuir o vender, en forma dolosa y con fin de especulación comercial, objetos que ostenten falsificaciones de marcas protegidas por esta Ley, así como aportar o proveer de cualquier forma, a sabiendas, materias primas o insumos destinados a la producción de objetos que ostenten falsificaciones de marcas protegidas por esta Ley (Fracción adicionada DOF 17-05-1999).

También están estipuladas las sanciones a quienes infringen dicha disposición, que en términos legales serían "delincuentes", pero siguen en total impunidad:

Artículo 223 Bis.- Se impondrá de dos a seis años de prisión y multa de cien a diez mil días de salario mínimo general vigente en el Distrito Federal, al que venda a cualquier consumidor final en vías o en lugares públicos, en forma dolosa y con fin de especulación comercial, objetos que ostenten falsificaciones de marcas protegidas por esta Ley. Si la venta se realiza en establecimientos comerciales, o de manera organizada o permanente, se estará a lo dispuesto en los artículos 223 y 224 de esta Ley. Este delito se perseguirá de oficio ${ }^{15}$ (Artículo adicionado DOF 1705-1999. Reformado DOF 28-06-2010).

En estas disposiciones - y de su no cumplimiento- se ven contenidas tanto las oportunidades como los obstáculos para la protección de los productos de Marca. De ello se desprenden al menos tres

\footnotetext{
${ }^{15}$ Subrayado mío.
} 
consideraciones: la primera es que en la Ley de Propiedad Industrial están claramente tipificadas tanto las infracciones administrativas como los delitos derivados de las falsificaciones de la marcas protegidas por esta Ley; la segunda, es la falta de su observación por parte de las empresas y personas físicas, y la tercera es la falta de su aplicación por parte de las autoridades, toda vez que en la misma ley se establece, como ya se indicó, que "este delito se perseguirá de oficio" (Art. 223 Bis, LPI).

Esta serie de fallas retrasa el avance de una cultura de la legalidad que puede fomentarse mediante la protección con Indicación Geográfica a los productos vinculados a su origen. Pero, simultáneamente es necesario que se cumpla, empezando por las autoridades, con el Estado de Derecho, lo cual sigue siendo "mucho pedir" a la mayoría de las autoridades de este país.

La contraparte y consecuencia de estas fallas — derivadas de una cultura de ilegalidad y simulación — es la acelerada tendencia a la desaparición de los productos auténticos. Su falta de valoración cultural, rentabilidad económica y protección oficial — que pudiera revertir esa tendencia - incide fuertemente en el desánimo de los productores y demás actores sociales que luchamos por lograr la protección de los productos auténticos. A partir de la protección se consigue un desarrollo territorial más equilibrado entre regiones, donde cada una base su continuidad cultural precisamente en sus sistemas de producción tradicionales, de los cuales salen estos productos de alta densidad cultural, reconocimiento social y potencial económico; valores todos ellos socavados por esa cultura de la ilegalidad, de la corrupción y de la simulación e impunidad que prevalece en gran parte de quienes están oficialmente a cargo de su combate.

\section{Adecuar los marcos normativos y cumplir con el estado de derecho}

Para no seguir rezagándonos como país y perdiendo patrimonio como pueblo frente al ineludible avance de la globalización, incluso para sacar provecho de la misma, se debe seguir cerrando filas desde la sociedad civil aliada a académicos, funcionarios, políticos, religiosos conscientes de esta situación y comprometidos con la cultura de la legalidad, para 
una acción colectiva conjunta y organizada en contra de la corrupción, de la impunidad y de la simulación. La brújula que puede marcar un rumbo común a cada frente de batalla es la de seguir tratando de adecuar los marcos legales e institucionales a las múltiples realidades de los campesinos y artesanos del país, en lugar de seguir contribuyendo - directa o indirectamente- con la terquedad institucional de tratar de adecuar la realidad a los marcos normativos cada vez más viciados.

Es de advertir que dichas adecuaciones son necesarias pero no serán suficientes debido a que el centro del problema está más en la falta de aplicación de las leyes — como se ha demostrado con la LPI que ya existe- que en lo inadecuado de las mismas o en su inexistencia. Sin embargo, y para el tema que tratamos, es necesario que se tenga una ley y una institución que, en paralelo a la ley y al instituto de propiedad industrial ya existentes, atiendan específica y adecuadamente al sector y a la propiedad artesanal del país.

De entrada habría que ampliar la definición de artesanías que se tiene en el Fondo Nacional para las Artesanías (Fonart). Además de los objetos reconocidos como artesanías y diferenciados mediante Manualidades e Híbridos, ${ }^{16}$ en la definición deberían entrar todos los productos obtenidos mediante procesos artesanales, especialmente alimentos y bebidas, medicamentos y cosméticos. Bajo una consideración de sentido común, el objeto o producto que se obtiene de un proceso artesanal obviamente debe ser definido como artesanía, y ser atendido como tal por las instituciones correspondientes que hasta la fecha los excluyen.

A partir de esa inclusión oficial de los diversos y abundantes productos artesanales que todavía existen en el país, se podrían aplicar recursos para procurar su reconocimiento, revaloración, protección legal y un fomento económico adecuado a las condiciones peculiares de cada población, de acuerdo con su cultura y con sus condiciones económicas y ambientales. Bajo estas directrices, el IMPI y otro organismo similar que se cree ex profeso para proteger la propiedad artesanal podrían iniciar el proceso de proteger con Indicación Geográfica, Denominación de Origen, Marca Colectiva, y otras categorías que pudieran incluirse en una ley específica para la protección de la procedencia y vínculos

${ }^{16}$ Véase, http://www.fonart.gob.mx/web/pdf/DO/mdma.pdf. 
territoriales que tienen los procesos y los productos artesanales de alta densidad cultural.

En corolario, se trata de construir colectivamente y con el actuar cotidiano formar un frente de lucha para salvaguardar los diversos patrimonios con los que aún se cuenta en las distintas poblaciones y regiones de este país. Simultáneamente se requiere reconstruir el marco legal — con una Ley de Propiedad Artesanal— e institucional — con un Instituto Mexicano de la Propiedad Artesanal y un Fonart que amplíe su definición de artesanía además de los apoyos a todo producto obtenido y/o procesado artesanalmente-, esto es, que protejan efectivamente el patrimonio biocultural derivado de las diversas tradiciones y geografías de los pueblos de México.

En este mismo orden de ideas, con la adecuación de dichos marcos se espera que las figuras de protección legal favorezcan el inicio y adecuado desarrollo de procesos de patrimonialización para los abundantes productos tradicionales y las diversas formas, medios y concepciones de vida que encontramos, hasta ahora tan abundantes como desprotegidas y denostadas por las instituciones gubernamentales y las grandes empresas, por todo lo largo y ancho del territorio mexicano.

\section{Conclusiones}

El caso del queso Cotija nos muestra que aun cuando se lleva un largo camino recorrido en la organización formal de productores, en el esfuerzo y reconocimiento socio institucional del proceso de patrimonialización, en la protección legal mediante la Marca Colectiva y su posicionamiento en nuevos nichos de mercado, en la mejora de su calidad y del precio para los productores, todavía faltan vencer muchos obstáculos, como son: la infraestructura básica en los ranchos de la región, los canales y mecanismos para su comercialización formal, la adecuación de los marcos normativos e institucionales, la difusión amplia de los hallazgos científicos relativos a la inocuidad del queso y la protección legal efectiva de su marca.

Como podemos observar, siguen siendo más fuertes y numerosos los obstáculos que enfrenta este proceso de revaloración cultural y económica del producto artesanal, que las oportunidades que se han abierto hasta 
ahora para este producto, pero sobre todo para las familias que siguen manteniendo la forma de vida que le da sustento a esta tradición.

Los pueblos que han mantenido hasta el presente los conocimientos ancestrales y los procesos tradicionales para la obtención de productos primarios — de recolección, extracción y producción agrícola, ganadera, pesquera, forestal- y para su transformación mediante procesos artesanales, siguen viviendo un estado de indefensión jurídica y comercial. No cuentan con reconocimientos y registros que protejan de imitaciones $\mathrm{y}$ falsificaciones a sus productos $\mathrm{y}$ a sus lugares de origen, pese a su alta densidad cultural y fuerte anclaje a un territorio; dos aspectos que les dan su distinción, identidad y calidad diferenciada, generalmente no retribuida en sus intercambios comerciales ni tampoco reflejada en la normatividad institucional.

En dichas condiciones aumenta la impotencia - y la de quienes luchamos a su lado por mantener sus patrimonios - al constatar cómo a través de las reformas legislativas, institucionales y normativas realizadas "a modo" para el capital y grupos de poder político y económico, las instancias oficiales llevan a la clandestinidad los procesos y productos artesanales que han sido y podrían seguir como una imprescindible base del desarrollo y fuente del sustento material y simbólico de las familias y grupos culturales que conservan esos patrimonios bioculturales en México.

\section{Bibliografía citada}

Álvarez, Rubén, Esteban Barragán y Patricia Chombo, 2005, Reglas de Uso Marca Colectiva Queso Cotija Región de Origen, Colmich/ Ciatej, México.

Barragán, Esteban, 2003, "Por una orientación plural del porvenir. Proceso de certificación y patrimonio cultural en la Sierra de Jalmich”, en Oscar González (compilador), Estudios Michoacanos, El Colegio de Michoacán, Zamora, Michoacán, pp. 219-243.

Barragán, Esteban, 2010, "Con el patrimonio en sus manos”, en Esteban Barragán López, el queso cotija región de origen. siempre a su mesa, Icatmi, Morelia, Michoacán, pp. 11-45. 
Barragán, Esteban y Martha Chávez, 1998, "El queso Cotija se nos va de las manos", en V. Oikión (coordinador), Manufacturas de Michoacán, El Colegio de Michoacán/Gobierno del Estado de Michoacán, México, pp.189-219.

Barragán, Esteban y Pedro H. Ovando, 2015, “Gestión cultural de un producto artesanal: queso Cotija región de origen", ponencia presentada en el 2do. Encuentro Nacional de Gestión Cultural: Diversidad, tradición e innovación en la gestión cultural, Sistema de Universidad Virtual de la UdeG, Tlaquepaque, Jalisco, octubre.

Boucher, F. y G. J. Reyes, 2011, Guí metodológica para la activación de sistemas agroalimentarios localizados, IICA/CIRAD/RED-SIAL México-Europa, México.

Cervantes, Fernando, Abraham Villegas, Alfredo Cesín y Angélica Espinoza, 2008, Los quesos mexicanos genuinos. Patrimonio cultural que debe rescatarse, MPM/UACh/UAEM, México.

Escobar Zepeda, Grisel Alejandra, Maricarmen Quirasco Baruch y Fidel Alejandro Sánchez Flores, 2016, La Microbiota Bacteriana única del queso cotija y su potencial metabólico, revelados mediante Metagenómica, Departamento de Alimentos y Biotecnología, Facultad de Química, UNAM/Industria mexicana de CocaCola/Conacyt, México, en http://www.pnctacocacola.com.mx/

Fondo Nacional para las Artesanías/Secretaría de Desarrollo Social, 2009, Matriz de diferenciación entre Artesanía y Manualidad, Fonart, México.

Hernández, José de Jesús, 2016, "Komil, o del fracaso de las Denominaciones de Origen", Tecnoagave, Revista de la cadena del agave y sus derivados, núm. 41, Guadalajara, Jalisco, pp. 20-23.

Leff, Enrique, 2009, Filosofía Sudamericana, ISSE Publicación ocasional, núm. 6.

Ley de Propiedad Industrial, 1991, última reforma, DOF 09-04-2012, México.

Linck, Thierry y Esteban Barragán, 2015, "Las denominaciones de origen en México. El queso Cotija: entre confiscación y 
valorización patrimoniales", Carta Económica Regional núm. 115, Ineser-UdeG, pp. 114-135.

Linck, Thierry, Julio Moguel y Alfredo Ramírez, 2011, Economía popular y procesos de patrimonialización, Juan Pablos Editor/Fundación México social siglo XXI, México.

Linck, Thierry, Hermilio Navarro y Esteban Barragán, 2014, "Hacia una economía de la patrimonialización. Las apropiaciones colectivas de lo biótico y de lo cognitivo", en Humberto González y Margarita Calleja (coordinadores), en Dinámica Territorial Agroalimentaria en Tiempos de Glocalización, Universidad de Guadalajara, Guadalajara, México, pp. 69-98.

Poméon, Thomas, 2007, El queso Cotija, México. Un producto con marca colectiva queso "Cotija Región de Origen", en proceso de adquisición de una Denominación de Origen, consultoría para FAO e IICA, México.

\section{Referencias electrónicas}

Cevallos, Miguel Ángel, 2015, “¿Qué hay detrás del queso Cotija?”, Revista Siempre, México, en http://www.siempre.com. $\mathrm{mx} / 2015 / 11 /$

Cofocalec, en http://www.cofocalec.org.mx/catalogo/por_clave Gobierno Federal/SE/IMPI, 2010, "Las Marcas Colectivas y las Denominaciones de Origen", en http://www.wipo.int/edocs/ mdocs/geoind/es/wipo_geo_lim_11/wipo_geo_lim_11_6.pdf

Fonart, Fondo Nacional para el Fomento de las Artesanías, "Manual de diferenciación entre artesanía y manualidad, Secretaría de Desarrollo Social (Sedesol), Mexico, en http://www.canilec.org. $\mathrm{mx} /$ Circulares2011/DECLARATORIA de vigencia

Inapi, Ministerio de Economía Fomento y Turismo, Gobierno de Chile, “¿Qué son las indicaciones geográficas y las denominaciones de origen?, en http://www.inapi.cl/portal/institucional/600/ w3-article-750.html

Ministerio de Desarrollo Social, Gobierno de Argentina, en http:// www.desarrollosocial.gob.ar/buentrato/3587 